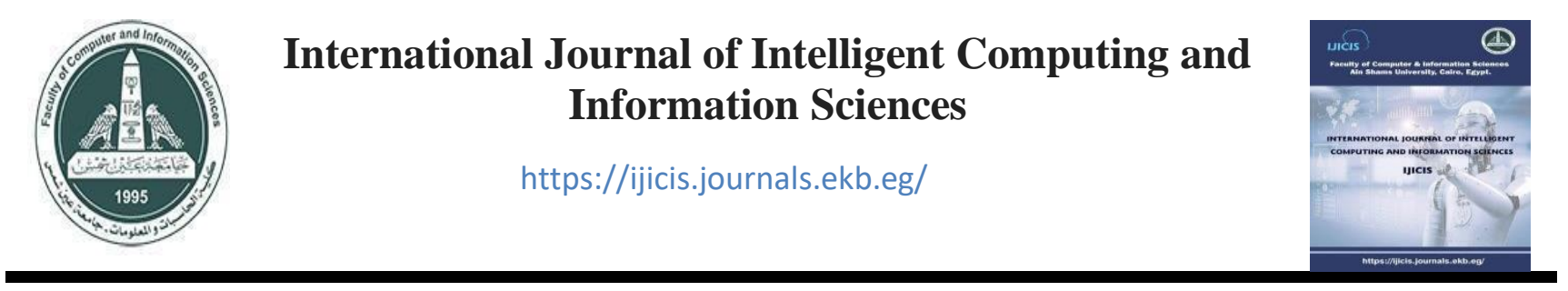

\title{
AUGMENTED REALITY IN TECHNOLOGY-ENHANCED LEARNING: SYSTEMATIC REVIEW 2011-2021
}

\author{
Rahma M. Tolba* \\ Computer Science Dept. \\ Faculty of Computer \& \\ Information Sciences, \\ Ain Shams University, Cairo, Egypt \\ rahma.tolba@cis.asu.edu.eg
}

\author{
Taha Elarif \\ Computer Science Dept. \\ Faculty of Computer \& \\ Information Sciences, \\ Ain Shams University, Cairo, Egypt \\ taha_elarif@cis.asu.edu.eg
}

\author{
Zaki T. Fayed \\ Computer Science Dept. \\ Faculty of Computer \& \\ Information Sciences, \\ Ain Shams University, Cairo, Egypt \\ ztfayed@hotmail.com
}

Received 2021- 09-22; Revised 2021-12-30; Accepted 2022-01-07

\begin{abstract}
With the raise of COVID-19 pandemic in 2020, the traditional teaching-learning process became inefficient. Technology-Enhanced Learning (TEL) research has increasingly focused on emergent technologies such as Augmented Reality (AR). It became one of the technologies that has received great attention and interest in the last decade. In this paper, we conducted a systematic review that describes the current state of using AR as a learning tool. Taking into consideration the needs of all students including those with a disability, in different levels of education. It is done through the analysis of the following factors: AR in learning system, AR in levels of education and categories of educational AR applications. A total of 103 studies between 2011 and 2021 were analyzed through searching in four interdisciplinary databases: Springer, IEEE Xplore, ResearchGate, and Google Scholar. This analysis helped to see in which direction AR systems for education are heading and how it will be designed to fit the students' needs and improve their learning. Further research and development will make AR a more promising learning tool.
\end{abstract}

Keywords: Augmented Reality, Education, TEL, AR Books, AR Applications.

\section{Introduction}

Since the term "Augmented Reality" was introduced in 1990 by Tom Caudell, became one of the technologies that have received great attention and interest in recent years [89]. The augmentation is typically done in real time and in semantic context with environmental elements. Augmented Reality (AR) enhances users' perception of reality by mixing the physical environment of the real world with a computer-generated virtual object. To view these objects, users either use smartphones, tablets, or wearable devices [89]. 
AR system consists of hardware, software, and application. The hardware are displays, sensors, processors, and input devices. The data is acquired from the real world through sensors. Then in Tracking, the processor analyzes the sensor inputs and chooses the appropriate virtual graphics to be displayed. At last, display devices are used to display the right virtual object in the right size and right coordinate on the real world as illustrated in Figure 1. The software allows AR applications to run on the used device but does not have the AR content. The AR content is existed in the AR application. The AR Software uses technologies, such as: Environment Understanding, Motion Tracking, and Light Estimation, to build the AR experience [102].

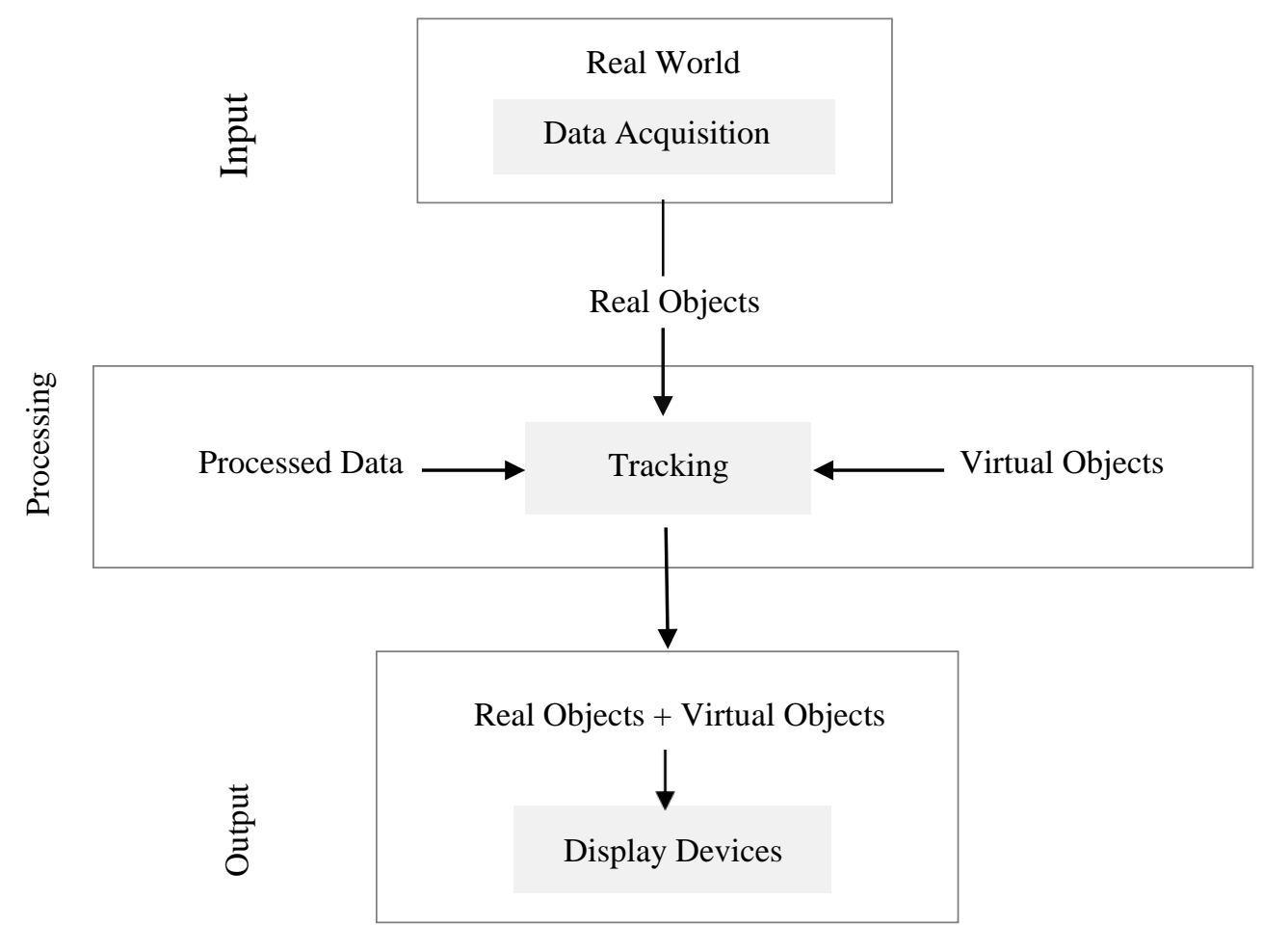

Figure 1: AR system [103].

There are four types of AR: see-through based, PC based, mobile based, and projection based [1]. Seethrough based AR uses Head Mounted Displays (HMD) such as Microsoft holo-lens to display the virtual objects. Where Mobile based AR uses mobile devices, such as smartphones and tablets, to blends the information from our senses with mobile devices in ways that were not possible before [2]. Mobile based AR also known as Mobile AR (MAR), is the most popular type among the four with 57\% according to Nizam's [1] review.

With the raise of COVID-19 pandemic in 2020, the traditional teaching-learning process of lectures, taking notes, reading facts from books, and taking exams, without striking minds of learners, became inefficient. Ever since all the efforts have turned to integrating the latest technologies in the educational process. Technology-Enhanced Learning (TEL) research has increasingly focused on emergent technologies such as Augmented Reality (AR) [3]. A considerable amount of literature has been published in using AR in educational contexts [4-10] due to the ability of AR to provide extra digital content for any subject that has some difficulties in understanding [52, 90, 94]. 
For example, Zainab and Huda [9] showed that "user satisfaction" is the most frequently mentioned positive impact of using AR in education. Yuen et al. [11] summarized five directions for AR in education. Belmonte et al. [12] did a scientific mapping in Web of Science about AR in education field. Altinpulluk [13] and Fidan [14] used the content analysis technique to determine the trends and features of using $\mathrm{AR}$ in education. A list of benefits of using $\mathrm{AR}$ in education has been mentioned by Horváthová in [53].

The rest of this paper is organized as follows: Section 2, discuss the methodology of our study, followed by the results of the systematic review in section 3. Finally, we concluded our work with suggestions for future work in section 4.

\section{Methodology}

The methodology used in this paper is a systematic review. First, we design the research questions then we collected data related to these questions from literature reviews, conference proceedings, journals, thesis, and books. Using PRISMA checklist methodology helped us to evaluate the used papers as a basis for reporting systematic review. Figure 2 illustrates the research steps.
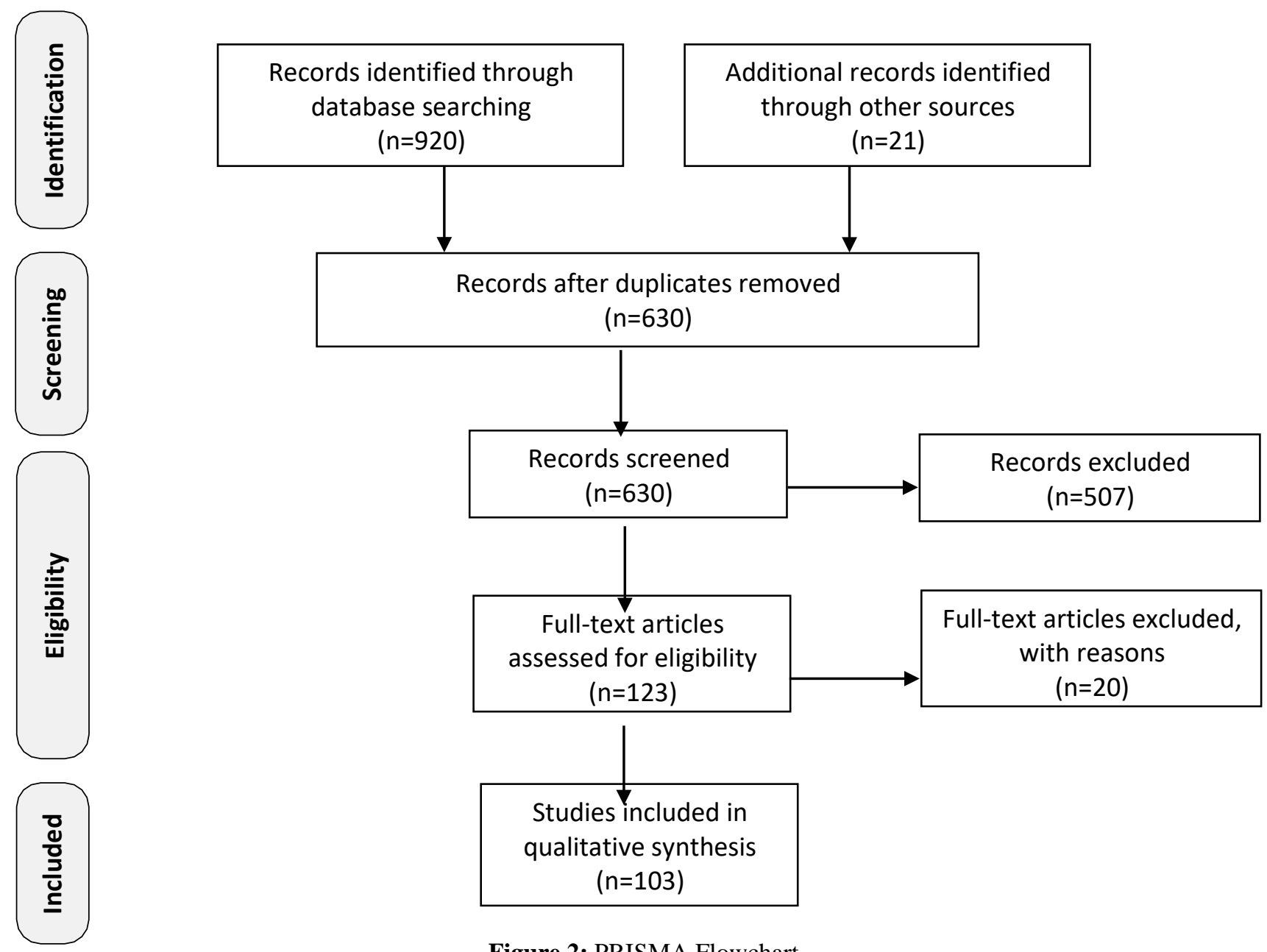

Figure 2: PRISMA Flowchart. 
The aim of this systematic review is to show the current state of using AR as learning tool in the last decade and how that enhanced the learning process. It addresses the following research questions:

- RQ1: How AR is integrated in the learning system?

- RQ2: How AR is used in different levels of Education?

- RQ3: What is the existing AR educational applications and its categories?

To select the research papers that answer mentioned research questions, certain inclusion and exclusion criteria are used. These criteria are showed in Table 1.

Table 1: The used inclusion and exclusion criteria.

\section{Inclusion Criteria}

- English research articles published between 2011 and 2021.

- Review studies that have domain in using AR in education and learning process.

- Papers that describe AR applications that support the process of learning certain subject.

- Articles about AR educational games.

- Studies that indicate the different levels of education that support AR as a learning tool.

- Books and thesis related to using AR as a learning tool.

\section{Exclusion Criteria}

- Papers that are duplicated.

- Publications that didn't contain terms 'AR' and 'Education'.

- Studies that refer to using virtual reality in education.

- Old review studies that already covered in the latest reviews.

As research sources, four multidisciplinary databases were selected. They are Springer, IEEE Xplore, ResearchGate, and Google Scholar. The first search was made on 24 March 2021, and the last on 20 Sep of the same year. The findings are discussed in the Results section.

\section{Results}

In this section we describe the obtained results. Then the findings according to each research question are discussed. 920 research papers were found using the search strings shown in Table 2. After applying the inclusion and exclusion criteria, 103 papers are used for this systematic review. Considering the title and abstract of each literature and cross-checking the results of the four databases to discard repeated documents. Table 3 shows the main characteristics of the used articles.

\subsection{RQ1: How AR is integrated in the learning system?}

The best way to learn is by doing rather than reading or listening. The more the senses like sight, sound, touch involved while learning the powerful the learning experience is. That's why the AR is used in making educational games [15,16] and in enhancing the distance learning process [17]. Li et al. found through their literature review [16] that AR educational games enhanced the learning performance and the learning experience in terms of fun, interest, and enjoyment. Where Krüger and Bodemer [54] showed the different types of interaction with the AR learning material and how that influenced the learning process and its outcomes. Martin et al. [55] discussed using AR as a part of a modular learning system to emerge education for Industry 4.0. 
Table 2: The search strings used for each database.

\begin{tabular}{|c|c|}
\hline Databases & Search Strings \\
\hline \multirow{13}{*}{$\begin{array}{l}\text { - Springer. } \\
\text { - IEEE Xplore. } \\
\text { - ResearchGate. } \\
\text { - Google Scholar. }\end{array}$} & Augmented Reality AND in AND Education. \\
\hline & Augmented Reality AND and AND TEL. \\
\hline & Augmented Reality AND for AND STEAM AND Learning. \\
\hline & Augmented Reality AND Educational AND Application. \\
\hline & Augmented Reality AND in AND Learning System. \\
\hline & Augmented Reality AND in AND Schools. \\
\hline & Augmented Reality AND for AND Distance Learning \\
\hline & Augmented Reality AND for AND Higher Education. \\
\hline & Augmented Reality AND in AND University. \\
\hline & Augmented Reality AND games AND for AND Learning \\
\hline & Augmented Reality AND for AND Learning. \\
\hline & Augmented Reality AND for AND Teachers. \\
\hline & Augmented Reality AND for AND Students. \\
\hline
\end{tabular}

Table 3: Main characteristics of used articles.

\begin{tabular}{|c|c|}
\hline Articles & Main Characteristics \\
\hline$[1-10], 16,18,24,41,52,92$ & Review and survey papers that discuss using AR in Education. \\
\hline$[15-22],[54-57], 95$ & Studies that show how AR is used in the learning system. \\
\hline 91, [96-98] & $\begin{array}{l}\text { Studies that investigated the use of AR in the learning systemin different } \\
\text { countries. }\end{array}$ \\
\hline$[23-32], 55,[58-60], 92,93,99$ & $\begin{array}{l}\text { Studies related to using AR in different levels of education(pre-school, } \\
\text { primary school, secondary school, and University). }\end{array}$ \\
\hline [33-36], [61-64], 100 & $\begin{array}{l}\text { Tools that help both teachers and students to create AR } \\
\text { content. }\end{array}$ \\
\hline $35,37,38,60,[65-71]$ & $\begin{array}{l}\text { AR Books that are acquiring augmented data by floating acamera on a } \\
\text { book's page to recognize its content. }\end{array}$ \\
\hline $39,[72-80], 92$ & Educational AR games published between 2011 and 2021. \\
\hline$[81,82,101]$ & $\begin{array}{l}\text { Studies about using AR to help students with disabilities tolearn and } \\
\text { communicate effectively. }\end{array}$ \\
\hline$[40-50], 72,82,[85-88], 101$ & $\begin{array}{l}\text { Subject specific AR applications that present interactive contents for a } \\
\text { specific set of knowledge. }\end{array}$ \\
\hline [94-101] & Thesis about AR in Education. \\
\hline [89-93] & Book chapters that discuss using AR technology in Education. \\
\hline
\end{tabular}


Garzón [18] and Ozdemir [19] provided Meta-analysis of the AR impact on students' learning gains. Findings indicated that AR applications increase students' academic achievement in the learning process compared to traditional methods [18]. Another analysis has been presented by Schmitz et al. in [56] to evaluate how these games impact the students' motivation and knowledge gain. The attention, satisfaction, and confidence factors of motivation were increased as found by Khan et al. in [20]. Hanid et al. [21] reveled the dominant strategies that use AR in education. These strategies are interactive learning, game-based learning, collaborative learning, and experiential learning [95]. Among the four types of learning strategies, interactive learning is the most reported in this meta-analysis review. AR also has great potentials in open and distance learning as discussed by Saykili and Altınpulluk in [22,57]. Researchers have investigated the use of AR in the learning system of different countries such as India [91], Australia [96], Bangladesh [97], USA and Kuwait [98].

\subsection{RQ2: How AR is used in different Levels of Education?}

AR is currently being applied across disciplines in primary, secondary, and higher education, and has been found to increase the academic success levels and motivations of students. We investigated the studies published between 2011 and 2021, that are related to using AR in the different levels of education. The number of reviewed articles for each level is illustrated in Figure 3.

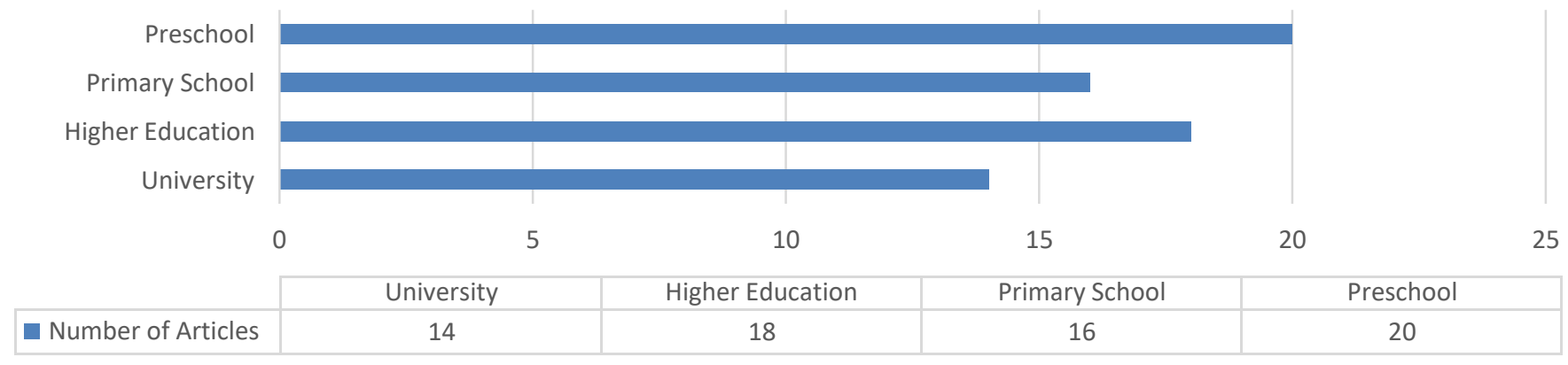

Figure 3: Number of reviewed articles for each level of education.

Mohamudally covered in his book [92] all major studies related to pre-school, primary school, and secondary school. Leighton [93] and Pedaste [23] discussed the affordances of using AR in K-12 Education. Pellas et al. [24] reported a systematic review of using ARGBL (AR with Game-Based Learning) across various primary and secondary education subjects. This review offered new insights on integrating ARGBL in learning system to increase student motivation and improve learning outcomes and the learning experience. Where Silva et al. [58] investigated why AR not used in schools.

Although some may be hesitant to adjust their curriculum to accommodate AR, higher-education professionals should at least be aware of how AR can shape teaching and learning, as current students become accustomed to use such technology in their daily life [25]. Thomas et al. [25] discussed that in their review. They also discussed pedagogical benefits and challenges of implementing AR in higher education. Jamali et al. [26] proposed an MAR (Mobile AR) framework for higher education that can enhance learners' motivation and attention especially when dealing with complex objects, like learning human anatomy. Sinha [27] discussed the role of AR application in Higher Education Learning. Huisinga [99] explored in her dissertation the effects of using AR to support reading in higher 
education. Stojšić et al. [28] discussed students' attitudes toward using MAR in higher education focusing on augmented textbooks. Moreover, AR is started to be used in the University environments such as Technical University [59], King Faisal University [29], FuJen University [30], Comenius University [31], Taiwanese University [32], Massachusetts Institute of Technology (MIT) and Harvard University [60].

\subsection{RQ3: Existing AR Educational Applications and its Categories.}

Unlike other computer interfaces that draw users away from the real world and onto the screen, AR interfaces enhance the real-world experience [61]. The proposed AR applications for Education can be categorized into applications to create the AR content, AR books, AR games, and subject specific applications [51]. 37 studies between 2011 and 2021 were collected and summarized for each category in Tables 4, 5, 6, and 7, respectively. Each Table shows the application's name, and brief information about the application. Table 4 shows examples of the applications that helps both teachers and students to create their AR content. Chookaew et al. [62] employed the advantages of AR to motivate the preservice teachers to construct their teaching materials. Where Silva [63] investigated how teachers use AR in their lesson. Lytridis et al. developed ARTutor, an AR platform, which enables teachers [33] and students [34] to create augmented books.

Table 4: Tools that help both teachers and students to create the AR content.

\begin{tabular}{|c|l|}
\hline Tool's Name & \multicolumn{1}{|c|}{ Description } \\
\hline Vuforia Chalk [100] & It allows students to annotate live video feeds remotely. \\
\hline GeoGebra [35] & Teachers use it to visualize geometry, algebra, statistics, and calculus. \\
\hline MagicToon [36] & $\begin{array}{l}\text { An interactive modeling system with MAR that allows children to build 3D } \\
\text { cartoonscenes creatively from their own 2D cartoon drawings on paper. }\end{array}$ \\
\hline VEDILS [64] & $\begin{array}{l}\text { A visual tool based on the MIT App Inventor 2 environment for designing } \\
\text { interactivelearning scenarios and can be deployed on Android devices. }\end{array}$ \\
\hline ARTutor [33] & $\begin{array}{l}\text { AR platform, which enables teachers [33] and students [34] to create } \\
\text { augmented books. }\end{array}$ \\
\hline
\end{tabular}

The concept of any AR book is acquiring augmented data by floating a camera on a book's page to recognize its content. This concept is used to make the educational books more interactive [35]. It also helps the students comprehend any given point in the academic book without the need to search the internet to get the information needed [37]. In Table 5 we show examples of AR Books that have been published in studies between 2011 and 2021.

With the existence of interactive games and advanced communication tools, the traditional teaching methods find no place. To avoid the academic procrastination, game activity is embedded in the AR tool as suggested by Ibanez in [72]. Examples of published educational AR games between 2011 and 2021 are showed in Table 6. 
Table 5: Examples of AR Books that published in studies between 2011 and 2021.

\begin{tabular}{|c|l|}
\hline Name & \multicolumn{1}{|c|}{ About } \\
\hline Historia & $\begin{array}{l}\text { AR application that reinforcement History subject for the second level of a } \\
\text { public highschool in Ecuador [60]. }\end{array}$ \\
\hline Magical Playbook & $\begin{array}{l}\text { It augments a 3D character and animation with audio onto the marker page of the } \\
\text { book [38]. }\end{array}$ \\
\hline 3D Pop-UpBook & $\begin{array}{l}\text { It employs storytelling as a teaching technique in a blended learning environment } \\
\text { for gradethree students in Bangkok to learn English language [65]. }\end{array}$ \\
\hline GeoAR & $\begin{array}{l}\text { An interactive book which incorporates AR resources. It supports the process } \\
\text { of teachingand learning of Geometry topics [66]. }\end{array}$ \\
\hline APPLearn(Heart) & $\begin{array}{l}\text { It allows students to learn about the cardiac structure and its function through } \\
\text { interactiveplaying [67]. }\end{array}$ \\
\hline Inpresso AR & It can download and play different AR experiences for any existing book [68]. \\
\hline MyVision AIR & $\begin{array}{l}\text { It aims to enhance the reading experience of adult-learners by incorporating AR } \\
\text { content tonormal books [69]. }\end{array}$ \\
\hline Research App & $\begin{array}{l}\text { It enables the students to visualize the African continent in 3D on their } \\
\text { smartphones. Bymodeling maps from the textbook [70]. }\end{array}$ \\
\hline wARna & $\begin{array}{l}\text { A mobile-based app that augments a coloring book with user-manipulated 3D } \\
\text { contents[71]. }\end{array}$ \\
\hline
\end{tabular}

Table 6: Examples of Educational AR Games published between 2011 and 2021.

\begin{tabular}{|c|l|}
\hline Application's Name & \multicolumn{1}{c|}{ About } \\
\hline PlanetarySystemGO & It consists of a location-based game to learn about the Universe [39]. \\
\hline ABC3D & It enhances preschool-aged children's knowledge of print-based literacy [73]. \\
\hline EduPARK & MAR game that aims to promote learning in an urban park [77]. \\
\hline FootMath [75] & $\begin{array}{l}\text { It visualizes, manipulates, and explores mathematical functions, through the } \\
\text { simulation of a 3D football game, in which the user can change the function } \\
\text { parameters with different values, to score a goal. }\end{array}$ \\
\hline AR-Maze & $\begin{array}{l}\text { It uses a designated image (Location Map) as a marker and displays a 3D scene } \\
\text { on top of it. Players control the AR scene to provide the image, textual andaudio } \\
\text { feedback superimposed on the real scene [76]. }\end{array}$ \\
\hline CodeCubes & $\begin{array}{l}\text { The AR game is composed of three levels. It consists of programming a car } \\
\text { course in a racetrack, driving from the start to the final goal [77]. }\end{array}$ \\
\hline Kotak Edu [78] & $\begin{array}{l}\text { It enhances early childhood knowledge of animal in a relaxed and fun way with } \\
\text { AR features. }\end{array}$ \\
\hline SolarSystemGO & $\begin{array}{l}\text { It provides awareness of the vastness and proportionality of the Solar System } \\
\text { objects, such as the Sun and the planets [79]. }\end{array}$ \\
\hline Conserv-AR & $\begin{array}{l}\text { a mobile game application that employs virtual and augmented reality concepts } \\
\text { alongside games design to increase awareness and knowledge surrounding } \\
\text { environmental conservation in Western Australia [80]. }\end{array}$ \\
\hline
\end{tabular}


AR increased students' achievements in STEAM (Science, Technology, Engineering, Arts, and Mathematics) education [40,41]. It also helps students with disabilities to learn and communicate effectively [81,82,101]. Subject specific AR applications are developed and designed to present interactive contents for a specific set of knowledge [101]. Examples of these subject specific applications are collected in Table 7.

Table 7: Examples of subject specific AR applications published between 2011 and 2021.

\begin{tabular}{|c|c|c|}
\hline Application's Name & Subject & About \\
\hline Teach Me A Story & History & $\begin{array}{l}\text { It is for secondary student. It helps them to be aware of the } \\
\text { notions of political / economic power of civilization. [83] }\end{array}$ \\
\hline PCBuildAR & $\begin{array}{l}\text { Computer } \\
\text { Science }\end{array}$ & $\begin{array}{l}\text { It uses } 8 \text { cards to help computer science students learn and } \\
\text { practiceabout the classic computer system [84]. }\end{array}$ \\
\hline $\begin{array}{l}\text { Augmented Polyhedrons } \\
\text { - Mirage } 2.2\end{array}$ & Math & It visualizes 3D mathematical polyhedrons [72]. \\
\hline Leihoa & $\begin{array}{l}\text { English as a } \\
\text { second } \\
\text { Language }\end{array}$ & $\begin{array}{l}\text { It aims to initiate reading, introduce numbers, and motivate } \\
\text { exploration of rich vocabulary in English as a second language } \\
\text { [42]. }\end{array}$ \\
\hline Geometry Learning & Geometry & $\begin{array}{l}\text { It uses the magic book to enable the students see } 3 \mathrm{D} \text { shapes } \\
\text { basedon the materials they learn. [43]. }\end{array}$ \\
\hline AR App & Calculus & $\begin{array}{l}\text { It promotes spatial visualization in Calculus courses for } \\
\text { engineeringstudents [44]. }\end{array}$ \\
\hline GeometAR & Geometry & $\begin{array}{l}\text { It provides the possibility to type in mathematics information } \\
\text { suchas equations of planes, lines, via a plus-button [85]. }\end{array}$ \\
\hline ARGE3D & Geometry & $\begin{array}{l}\text { It is for geometric objects that is contained in the } \\
\text { mathematicscurriculum of 6th class of primary education [45]. }\end{array}$ \\
\hline AR Math Learning & Geometry & $\begin{array}{l}\text { It introduces digital leaning materials on 'Pillar' unit of Math } \\
\text { for } 6^{\text {th }} \text {-grade elementary school students [46]. }\end{array}$ \\
\hline $\begin{array}{l}\text { Mobile Programming } \\
\text { with MIT App Inventor }\end{array}$ & Programming & $\begin{array}{l}\text { It is for the higher education course "Advanced Mobile } \\
\text { Applications" [47]. }\end{array}$ \\
\hline Research App & Excel & It guides the students to perform Excel operations [86]. \\
\hline HyperCubes & Programming & AR platform to foster computational literacy [87]. \\
\hline WARCSB [48] & Science & Web AR for Chemistry and Structural Biology portal. \\
\hline AR-SaBEr [49] & Science & $\begin{array}{l}\text { A simulation tool based on } \mathrm{AR} \text { to discover the basic principles } \\
\text { ofelectricity through a series of experiments. }\end{array}$ \\
\hline PlanetarySystemGO & Science & $\begin{array}{l}\text { It provides the experience of interacting with any planetary } \\
\text { systemof the Universe [88]. }\end{array}$ \\
\hline
\end{tabular}


We found that Science is the most explored field. Comes next Mathematics, History and Programing as illustrated in Figure 4. The figure shows the number of reviewed articles for each of top four fields (Science, Mathematics, History and Programming).

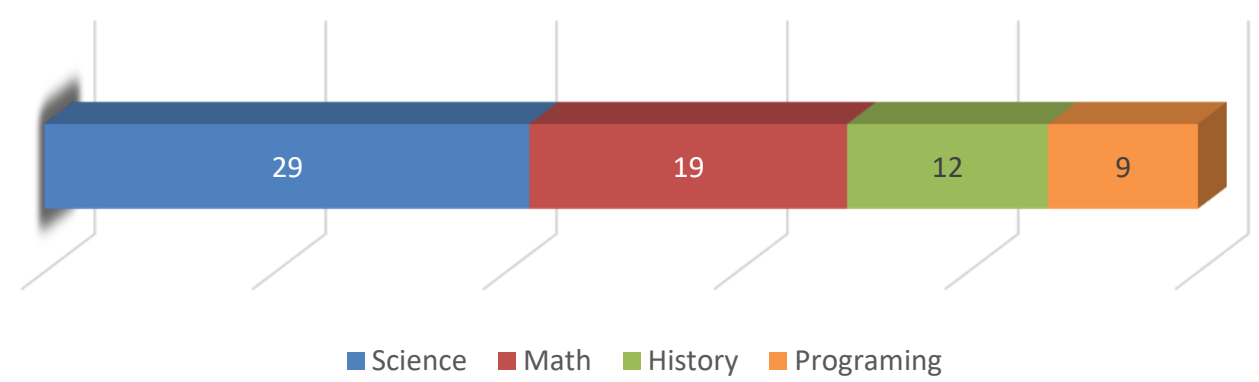

Figure 4: The number of reviewed articles for the top four fields of Education (Science, Math, History, and Programming).

\section{Conclusion and Future work}

As conclusion, AR showed a great potential and benefits in the education sector [9]. It can be designed to stimulate any academic scenario. It has been used mostly in science education and medical training [50]. It helped the students to be more motivated and engaged with the learning materials. It has been used and explored in all levels of education. Yet AR needs to be integrated more in university martials. Several review papers stated that the development of AR should consider the pedagogical aspect between the user and the application to provide an easy learning experience. Teachers should be able to add or update the contents easily. AR devices need to be developed in way that is easy to use and carry [10]. That is the reason behind using mobile devices in most of the reviewed articles. In other words, most of the research papers tried to solve educational problems through developing MAR systems which results in successful learning outcomes.

It is believed that the results obtained in this study will light the way for future research in other fields of education such as Art, Programming and Language Learning. Future research should look at pedagogical use of MAR in those fields. For example, MAR could be used to enhance the experience of learning programming in an interactive way not only projecting virtual informative objects. Researchers can enable these objects to show different reactions based on students' inputs. It is expected that AR will acquire greater relevance in teaching-learning process in the upcoming years [9]. 


\section{References}

1. S. Nizam, R. Abidin, and N. Hashim et al., "A Review of Multimodal Interaction Technique in Augmented Reality Environment", International Journal on Advanced Sciences Engineering Information Technology, Vol. 8, No. 4-2, pp. 1460-1469, 2018.

2. D. Chatzopoulos, C. Bermejo, Z. Huang, And P. Hui, "Mobile Augmented Reality Survey: From Where We Are to Where We Go", IEEE Access, Vol. 5, 2017.

3. J. Bacca, S. Baldiris, R. Fabregat et al., "Augmented Reality Trends in Education: A Systematic Review of Research and Applications", Educational Technology \& Society Journal, Vol. 17(4), pp. 133-149, 2014.

4. J. Quintero1, S. Baldiris, R. Rubira, J. Cerón and G. Velez, "Augmented Reality in Eductional Inclusion. A systematic Review on the Last Decade", Front. Psychol. Vol 10, 2019.

5. M. Silva, J. Teixeira, P. Cavalcante, and V. Teichrieb, "Perspectives on how to evaluate augmented reality technology tools for education: a systematic review", The Brazilian Computer Society, Vol. 25(3), 2019.

6. C. Dalim, H. Kolivand, and H. Kadhim et al., "Factors Influencing the Acceptance of Augmented Reality in Education: A Review of the Literature”, Journal of Computer Sciences, Vol. 13(11). pp. 581-589, 2017.

7. J. Garzón, J. Pavón, and S. Baldiris, "Systematic review and meta-analysis of augmented reality in educational settings”, Virtual Reality, Springer, Vol.23, pp. 447-459, 2019.

8. D. VUȚĂ, “Augmented Reality Technologies in Education - A Literature Review”, Bulletin of the Transilvania University of Braşov Series V: Economic Sciences, Vol. 13(62) No. 2, 2020.

9. Z. Majeed and H. Ali, "A review of augmented reality in educational applications", International Journal of Advanced Technology and Engineering Exploration, Vol. 7(62), Jan 2020.

10. R. Lionoa, N. Amanda, A. Pratiwi, and A. Gunawan, "A Systematic Literature Review: Learning with Visual by th help of Augmented Reality Helps Students Learn Better", Procedia Computer Science, ELSEVIER, Vol. 179, pp. 144-152, 2021.

11. S. Yuen, G. Yaoyuneyong, and E. Johnson, "Augmented Reality: An Overview and Five Directions for AR in Education”, Journal of Educational Technology Development and Exchange, Vol. 4(1), pp. 119-140, Oct 2011.

12. J. Belmonte, A. Guerrero, J. Núñez, and F. Lucena, "Augmented reality in education. A scientific mapping in Web of Science", Interactive Learning Environments Journal, Dec 2020.

13. H. Altinpulluk, "Determining the trends of using augmented reality in education between 2006-2016", Education and Information Technologies Journal, March 2019.

14. M. Fidan and M. Tuncel, "Augmented reality in education research (2012-2017): A content analysis", Cypriot Journal of Educational Science, Vol.13(4), pp. 577-589, 2018.

15. M. Weerasinghe, A. Quigley, and J. Ducasse et al., "Educational Augmented Reality Games", Augmented Reality Games II, Springer (pp.3-32), 2019.

16. J. Li, E. Spek, and L. Feijs et al., "Augmented Reality Games for Learning: A Literature Review", DAPI, Springer, Vol. 10291. pp. 612-626, 2017.

17. S. Vafa, K. Sappington, and R. Richardson, "Using Augmented Reality to Increase Interaction in Online Courses", International Journal of Educational Technology and Learning, Vol. 3, No. 2, pp. 65-68, 2018.

18. J. Garzón and J. Acevedo, "Meta-analysis of the impact of Augmented Reality on students' learning gains", Educational Research Review Journal, Vol. 21, pp. 244-260, Elsevier, 2019. 
19. M. Ozdemir, C. Sahin, S. Arcagok, and M. Demir, "The Effect of Augmented Reality Applications in the Learning Process: A Meta- Analysis Study", Eurasian Journal of Educational Research (EJER), Vol. 74, pp. 165-186, 2018.

20. T. Khan, K. Johnston, and J. Ophoff, "The Impact of an Augmented Reality Application on Learning Motivation of Students", Advances in Human-Computer Interaction Journal, Article ID 7208494, 2019.

21. M. Hanid, M. Said, and N. Yahaya, "Learning Strategies Using Augmented Reality Technology in Education: Meta-Analysis", Universal Journal of Educational Research, Vol. 8, pp. 51-56, 2020.

22. H. Altınpulluk, M. Kesim, and G. Kurubacak, "The Usability of Augmented Reality in Open and Distance Learning Systems: A Qualitative Delphi Study”, Open Praxis, Vol. 12(2), pp. 283-307, 2020.

23. M. Pedaste, G. Mitt and T. Jürivete, "What Is the Effect of Using Mobile Augmented Reality in K12 InquiryBased Learning?”, Education Science Journal. Vol. 10(4), 2020.

24. N. Pellas, P. Fotaris, I. Kazanidis, and D. Wells, "Augmenting the learning experience in primary and secondary school education: a systematic review of recent trends in augmented reality game-based learning", Springer Ltd, Virtual Reality Journal, Vol. 23, pp. 329-346, 2019.

25. R. Thomas, K. Linder, and N. Harper et al., "Current and Future Uses of Augmented Reality in Higher Education”, IDEA Paper \#81, 2019.

26. S. Jamali, M. Shiratuddin, and K. Wong, "An Overview of mobile-Augmented Reality in Higher Education", Int. J. on Recent Trends in Engineering and Technology, Vol. 11(1), July 2014.

27. B. Sinha and S. Sahay, "Role of Augmented Reality Application in Higher Education Learning", Aegaeum Journal, Vol. 8(10), pp. 926-937, 2020.

28. I. Stojšić, A. Džigurski, and O. Maričić et al., "Students' Attitudes Toward the Application of Mobile Augmented Reality in Higher Education”, General Social Journal, Vol. 29(4), pp. 535-554, 2020.

29. D. Ismaeel and E. Al Mulhim, "Influence of Augmented Reality on the Achievement and Attitudes of Ambiguity Tolerant/Intolerant Students”, International Education Studies, Vol. 12, No. 3, 2019.

30. T. Chou and L. ChanLin, "Augmented Reality Smartphone Environment Orientation Application: A Case Study of the Fu-Jen University Mobile Campus Touring System”, Procedia - Social and Behavioral Sciences, Vol. 46, pp. 410-416, 2012.

31. M. Babinská, M. Dillingerová, and L. Korenova, "Augmented Reality and Future Mathematics Teachers", Augmented Reality in Educational Settings, Koninklijke Brill NV, pp. 236-263, 2020.

32. K. Chin and C. Wang, "Effects of augmented reality technology in a mobile touring system on university students' learning performance and interest”, Educational Technology Australasian Journal, Vol. 37(1), 2021.

33. C. Lytridis, A. Tsinakos and I. Kazanidis, "ARTutor-An Augmented Reality Platform for Interactive Distance Learning”, Education Sciences Journal, Vol. 8(1), pp. 6, 2018.

34. C. Lytridis and A. Tsinakos, "Evaluation of the ARTutor augmented reality educational platform in tertiary education”, Smart Learning Environments Journal, Vol. 5(6), Springer Ltd, 2018.

35. J. Jesionkowska, F. Wild, and Y. Deval, "Active Learning Augmented Reality for STEAM Education—A Case Study", Education Sciences, Vol. 10(8), 2020.

36. L. Feng, X. Yang, and S. Xiao, "MagicToon: A 2D-to-3D Creative Cartoon Modeling System with Mobile AR", IEEE Virtual Reality (VR), pp. 195-204, 2017.

37. P. Subhashini, R. Siddiqua, A. Keerthana, and P. Pavani, "Augmented Reality in Education", Journal of Information Technology and Digital World, Vol. 2, No. 4, pp. 221-227, 2020.

38. T A. Tomi and D. Rambli, "An Interactive Mobile Augmented Reality Magical Playbook: Learning Number With The Thirsty Crow”, Procedia Computer Science Journal, Elsevier, Vol. 25, pp. 123 - 130, 2013. 
39. M. Costa, A. Manso, and J. Patrício, "Design of a Mobile Augmented Reality Platform with Game-Based Learning Purposes", Information, Vol. 11(127), 2020.

40. H. Kamışlı and B. Öznacar, "The effect of augmented reality based mobile software on students' academic achievement", Intelligent Decision Technologies Journal, 2020.

41. M. Ibáñez and C. Kloos, "Augmented reality for STEM learning: A systematic review", Computers \& Education, ELSEVIER, Vol. 123, pp. 109-123, 2018.

42. A. Martínez, I. López, J. Benito and E. González, "Leihoa: A window to augmented reality in early childhood education", International Symposium on Computers in Education (SIIE), pp. 1-6, 2016.

43.D. Rohendi and Y. Wihardi, "Learning Three-Dimensional Shapes in Geometry Using Mobile-Based Augmented Reality", International Journal of Interactive Mobile Technologies (iJIM), Vol. 14 (9), 2020.

44. E. Quintero, P. Salinas, E. Mendívil, and H. Ramírez, "Augmented Reality app for Calculus: A Proposal for the Development of Spatial Visualization”, Procedia Computer Science Journal, Elsevier, Vol. 75, pp. 301-305, 2015.

45. E. Bi li ' and S. Ahi in, "The effect of augmented reality assisted geometry instruction on students' achievement and attitudes", Teaching Mathematics and Computer Scince Journal, Vol. 13 (2), pp. 177-193, 2015.

46. W. Chao and R. Chang, "Using Augmented Reality to Enhance and Engage Students in Learning Mathematics", Advances in Social Sciences Research Journal, Vol.5(12), 2018.

47. I. Kazanidis, A. Tsinakos, and C. Lytridis, "Teaching Mobile Programming Using Augmented Reality and Collaborative Game Based Learning", Interactive Mobile Communication Technologies and Learning (IMCL), Advances in Intelligent Systems and Computing, Springer, Vol 725, pp. 850-859, 2017.

48. R. Arslan, M. Kofoğlu, and C. Dargut, "Development of Augmented Reality Application for Biology Education", Journal of Turkish Science Education, Vol. 17(1), March 2020.

49. M. Ibáñez, A. Serio, D. Molina, and C. Kloos, "Augmented Reality-Based Simulators as Discovery Learning Tools: An Empirical Study”, IEEE Transactions on Education, Vol. 58(3), 2015.

50. A. Yassin, T. Elarif, and M. Hefny, "Augmented Reality System in Total Hip Arthroplasty Using Transverse Acetabular Ligament", International Journal of Intelligent Computing and Information Sciences (IJICIS), Vol. 20(2), pp. 79-88, 2020.

51. J. Cao, K. Lam, and L. Lee et al., "Mobile Augmented Reality: User Interfaces, Frameworks, and Intelligence", arXiv:2106.08710, 2021.

52. B. Hantono, E. Nugroho, P. Santosa, "Meta-Review of Augmented Reality in Education", $10^{\text {th }}$ International Conference on Information Technology and Electrical Engineering (ICITEE), Bali, Indonesia, 2018.

53. D. Horváthová, P. Voštinár, and M. Mitter, "Extended Reality in Education”, $13^{\text {th }}$ International Scientific Conference on Distance Learning in Applied Informatics DIVAI, 2020.

54. J. Krüger and D. Bodemer, "Different Types of Interaction with Augmented Reality Learning Material", $6^{\text {th }}$ International Conference of the Immersive Learning Research Network (ILRN), 2020.

55. J. Martin, J. Bohuslava, and H. Igor, “Augmented Reality in Education 4.0”, IEEE CSIT, pp. 231-236, Ukraine, 2018.

56. B. Schmitz, R. Klemke, and M. Specht, "An Analysis of the Educational Potential of Augmented Reality Games for Learning", $11^{\text {th }}$ World Conference on Mobile and Contextual Learning (mLearn), 2012.

57. A. Saykili, “Augmented Reality in Open and Distance Learning”, $8^{\text {th }}$ Teaching \& Education Conference, 2019. 
58. M. Silva, R. Roberto, L. Radu, and P. Cavalcante, "Why Don't We See More of Augmented Reality in Schools?", IEEE International Symposium on Mixed and Augmented Reality Adjunct (ISMAR-Adjunct) conference, 2019.

59. J. Guerrero, J. Mera, and W. López et al., "Use of Augmented Reality AR in University Environments", International Conference on eDemocracy \& eGovernment (ICEDEG), Ecuador, pp. 291-297, 2018.

60. D. Velasteguí, A. Noboa, and D. Vizueta et al., "Augmented Reality Implementation as Reinforcement Tool for Public Textbooks Education in Ecuador", IEEE Global Engineering Education Conference (EDUCON), pp. 1243-1250, Canary Islands, Spain, 2018.

61. M. Silva, R. Roberto, L. Radu, and P. Cavalcante, "Towards the Development of Guidelines for Educational Evaluation of Augmented Reality Tools", IEEE Virtual Reality Workshop on K-12 Embodied Learning through Virtual \& Augmented Reality (KELVAR), USA, 2016.

62. S. Chookaew, S. Howimanporn, and W. Sootkaneung et al., "Motivating Pre-Service Teachers with Augmented Reality to Developing Instructional Materials through Project-Based Learning Approach", $6^{\text {th }}$ International Conference on Learning Technologies and Learning Environments, Japan, 2017.

63. M. Silva, I. Radu, and B. Schneider et al., "An Investigation on How Teachers are Using Augmented Reality in Their Lessons", VII Brazilian Congress of Informatics in Education (CBIE), 2018.

64. J. Mota, I. Rube, J. Dodero, and M. Figueiredo, "Visual Environment For Designing Interactive Learning Scenarios with Augmented Reality", 12 ${ }^{\text {th }}$ International Conference on Mobile Learning, 2016.

65. P. Lan, “An Augmented Reality 3D Pop-Up Book: The Development of a Multimedia Project for English Language Teaching", IEEE International Conference on Multimedia and Expo, Australia, 2012.

66. T. Kirner, F. Reis, and C. Kirner, "Development of an interactive book with Augmented Reality for teaching and learning geometric shapes", $7^{\text {th }}$ Iberian Conference on Information Systems and Technologies (CISTI), Spain, 2012.

67. R. Ba, Y. Cai, and Y. Guan, "Augmented Reality Simulation of Cardiac Circulation Using APPLearn (Heart)", IEEE International Conference on Artificial Intelligence and Virtual Reality, Taiwan, 2018.

68. J. Rocha, L. Magalhães, N. Alves, and M. Guevara, "Inpresso AR: a generic Augmented Book", International Conference on Graphics and Interaction (ICGI), Portugal, 2019.

69. H. Ali, A. Bazzaza, M. Zenerly, and J. Ng, "MyVision AIR: An augmented interactive reality book mobile application", IEEE Global Engineering Education Conference (EDUCON), Abu Dhabi, United Arab Emirates, 2016.

70. A. Vahldick and D. Bittencourt, "Creating an Augmented Book from a Geography Textbook", IEEE $19^{\text {th }}$ International Conference on Advanced Learning Technologies (ICALT), Maceio, Brazil, 2019.

71. M. Norraji and M. Sunar, "wARna - Mobile-based augmented reality colouring book", $4^{\text {th }}$ International Conference on Interactive Digital Media (ICIDM), Indonesia, 2015.

72. M. Ibáñez and C. Delgado-Kloos, "Using an Augmented Reality Geolocalized Quiz Game as an Incentive to Overcome Academic Procrastination", International Conference on Interactive Mobile Communication, Technologies, and Learning (IMCL2018), pp. 264-272, 2018.

73. A. Bhadra, J. Brown, and H. Ke et al., "ABC3D - Using An Augmented Reality Mobile Game to Enhance Literacy in Early Childhood", IEEE International Conference on Pervasive Computing and Communications, 2016.

74. L. Pombo, M. Marques, and L. Afonso et al., "Evaluation of a Mobile Augmented Reality Game Application as an Outdoor Learning Tool”, International Journal of Mobile and Blended Learning, Vol. 11(4), 2019.

75. J. Cerqueira, J. Moura, C. Sylla, and L. Ferreira, "An Augmented Reality Mathematics Serious Game", First International Computer Programming Education Conference (ICPEC 2020), Article No. 6, pp. 1-8, 2020. 
76. Q. Jin, D. Wang, X. Dend, N. Zheng, and S. Chiu, "AR-Maze: A Tangible Programming Tool for Children Based on AR Technology", 17 $7^{\text {th }}$ ACM Conference on Interaction Design and Children, pp. 611-616, 2018.

77. B. Cleto, C. Sylla, L. Ferreira, and J. Moura, "CodeCubes: Coding with Augmented Reality", First International Computer Programming Education Conference (ICPEC 2020), Article No. 7, pp. 1-9, Germany, 2020.

78. V. Chrisna and T. Satria, "Kotak Edu: An Educational Augmented Reality Game for Early Childhood", $2^{\text {nd }}$ International Conference on Science \& Technology (ICoST), 2020.

79. J. Costa and J. Farropo, "SolarSystemGO - An Augmented Reality Based Game with Astronomical Concepts", $13^{\text {th }}$ Iberian Conference on Information Systems and Technologies (CISTI), Spain, 2018.

80. L. Phipps, V. Alvarez, and S. Freitas et al., "Conserv-AR: A Virtual and Augmented Reality Mobile Game to Enhance Students' Awareness of Wildlife Conservation in Western Australia", $15^{\text {th }}$ World Conference on Mobile and Contextual Learning, Vol. 1, pp. 214-217, Australia, 2016.

81. S. Deba, S. and P. Bhattacharyab, "Augmented Sign Language Modeling (ASLM) with interaction design on smartphone - an assistive learning and communication tool for inclusive classroom", $6^{\text {th }}$ International Conference on Smart Computing and Communications (ICSCC), India, 2017.

82. D. Maher, "Altered Realities: How virtual and augmented realities are supporting learning.", Handbook of Research on Innovative Pedagogies and Best Practices in Teacher Education, IGI Global, Jan 2019.

83. B. Schiavi, F. Gechter, C. Gechter, and A. Rizzo, "Teach Me A Story: An Augmented Reality Application for Teaching History in middle school", IEEE Conference on Virtual Reality and 3D User Interfaces, Germany, 2018.

84. J. Buchner and M. Kerres, "Applying Instructional Design Principles on Augmented Reality Cards for Computer Science Education”, EC-TEL 2020: Addressing Global Challenges and Quality Education, pp. 477 $481,2020$.

85.X. Reit, "Augmented Learning: Effects of Augmented Reality Supported Instruction on Spatial Ability", $12^{\text {th }}$ International Conference on Education and New Learning Technologies, pp. 6481-6485, 2020.

86. J. Zhang and K. Chang, "Applying Augmented Reality to Improve the Outcomes of Procedural Knowledge Acquisition”, 19 ${ }^{\text {th }}$ International Conference on Advanced Learning Technologies (ICALT), pp. 340-343, 2019.

87. A. Fuste and C. Schmandt, "HyperCubes: A Playful Introduction to Computational Thinking in Augmented Reality", CHI PLAY '19 Extended Abstracts: Extended Abstracts of the Annual Symposium on ComputerHuman Interaction in Play Companion Extended Abstracts, pp. 379-387, 2019.

88. A. Manso, M. Costa, J. Patrício, and A. Carvalho, "PlanetarySystemGO: An augmented reality application to explore the Universe", 15 ${ }^{\text {th }}$ China-Europe International Symposium on Software Engineering Education, 2019.

89. G. Kiryakova, "The Immersive Power of Augmented Reality", Human-Interaction Book, IntechOpen, May 2020.

90. M. Petrovich Jr.and A. Foster, "Augmented Reality in Research and Practice: A Content Analysis of Claims in Education", Designing, Deploying, and Evaluating Virtual and Augmented Reality in Education Book, IGI Global, pp. 8-75, 2020.

91. P. Sarkar and J. Pillai, "User Expectations of Augmented Reality Experience in Indian School Education", Research into Design for a Connected World Book, Ch. 63, pp. 745-755, Springer Ltd, 2019.

92. N. Mohamudally, "State of the Art Virtual Reality and Augmented Reality Knowhow" Book, IntechOpen, 2018.

93. L. Leighton and H. Crompton, "Augmented Reality in K-12 Education”, Technologies and Augmented Reality in Open Education Book, Ch. 14, IGI Global, 2017.

94. R. Sliusar, "Augmented reality as a future of the education, Case study of MoleQL - educational augmented reality application”, Master's Thesis, School of Information Technologies, Tallinn University, 2017. 
95. C. Casullo, "Augmented reality: Pedagogy and Educational Policy", Master Thesis, School of Education, Dublin University, 2020.

96. A. Michael, K. Patrick, and L. Anna et al., "KARLI - Kindgerechtes Augmented Reality Learn-Interface", Master Thesis, Polten University of Applied Sciences, 2018.

97. M. Hasan, I. Faiyaz, A. Bhuiyan, and S. Joy, "Augmented Reality Education System”, Thesis, Department of Computer Science and Engineering, BRAC University, 2018.

98. A. Almoosa, "A Qualitative Case Study in Augmented Reality Applications in Education: Dimensions of Strategic Implementation", PHD Thesis, Department of Educational Technology, Education and Behavior Sciences Collage, University of Northern Colorado, 2018.

99. L. Huisinga, "Augmented reality reading support in higher education: Exploring effects on perceived motivation and confidence in comprehension for struggling readers in higher education", PHD Thesis, Iowa State University, 2017.

100. M. Arbogast, "Immersive Technologies in Preservice Teacher Education: The Impact of Augmented Reality in Project-Based Teaching and Learning Experiences", PHD Dissertation, Curriculum \& Instruction: Educational Technology, Toledo University, 2019.

101. D. McMahon, "Augmented Reality on Mobile Devices to Improve the Academic Achievement and Independence of Students with Disabilities", PHD Thesis, University of Tennessee, Knoxville, 2014.

102. R. Chen, “our 3-Minute Guide to Augmented Reality (AR)" online article, https://www.constructdigital.com/insight/how-does-augmented-reality-ar-work, (accessed Sep 2021).

103. https://medium.com/@mafda /ar-101-components-of-the-augmented-reality-system-part-3-878c71e68069, (accessed in March 2021). 